\title{
Upgrade of existing algorithms for creating contour lines on topographic maps in karst surface
}

\author{
Neža Ema Komel ${ }^{\mathrm{a},}$, Dušan Petrovič ${ }^{\mathrm{a}}$ \\ ${ }^{a}$ University of Ljubljana, Faculty of Civil and Geodetic Engineering, Slovenia, Neža Ema Komel - neza.ema.komel@fgg.uni-lj.si, \\ Dušan Petrovič -dusan.petrovic@fgg.uni-lj.si \\ * Corresponding author
}

Keywords: contour lines, automatization, karst relief

\begin{abstract}
:
Relief is one of the basic elements of every topographic map. Usually, it is presented by a combination of contour lines, rock depictions and additional symbols of exposed relief objects. Contour lines as a basic relief presentation form were traditionally created by topographers. Their method of research was based on a stereoscopic photogrammetric survey. This method enabled a good morphological presentation; however, it was time consuming and strongly depended on the choice of the operator. The automated process of creating contour lines saves time; however, its result is of inferior quality in comparison with the lines created by topographers.
\end{abstract}

In our project we created an algorithm that upgrades contour lines, initially created in selected commercial software packages, with the focus on morphologically complex karts terrain. DMR 1 (LiDAR based Digital Elevation Model with 1 meter spatial density) was used as source relief data.

The created algorithm performs three main procedures with the following general functions: improving contour lines, creating point symbols of individual objects of relief (symbols for sinkholes and slope lines) and creating symbols for rock faces (area objects). Figure 1 depicts the algorithms diagram.

Calculated contour lines are divided classified into index, intermediate and supplementary contour lines based on their height attribute. The length of supplementary contour lines is optimized. Sinkholes and slope line symbols are calculated based on the length and the height of the lines which define sinkholes. Area symbols are generated based on the distance between contour lines, while hatching was created by neural network.

The algorithm was tested in four different areas of karst terrain in Slovenia. The comparison between contour lines created by the commercial software, symbols of landforms presented on national topographic map at a selected scale and the result of the created algorithm gives promising results.

The algorithm represents a step towards optimizing the production of relief presentation on topographic maps in the karst area. 
contour line created by commercial software

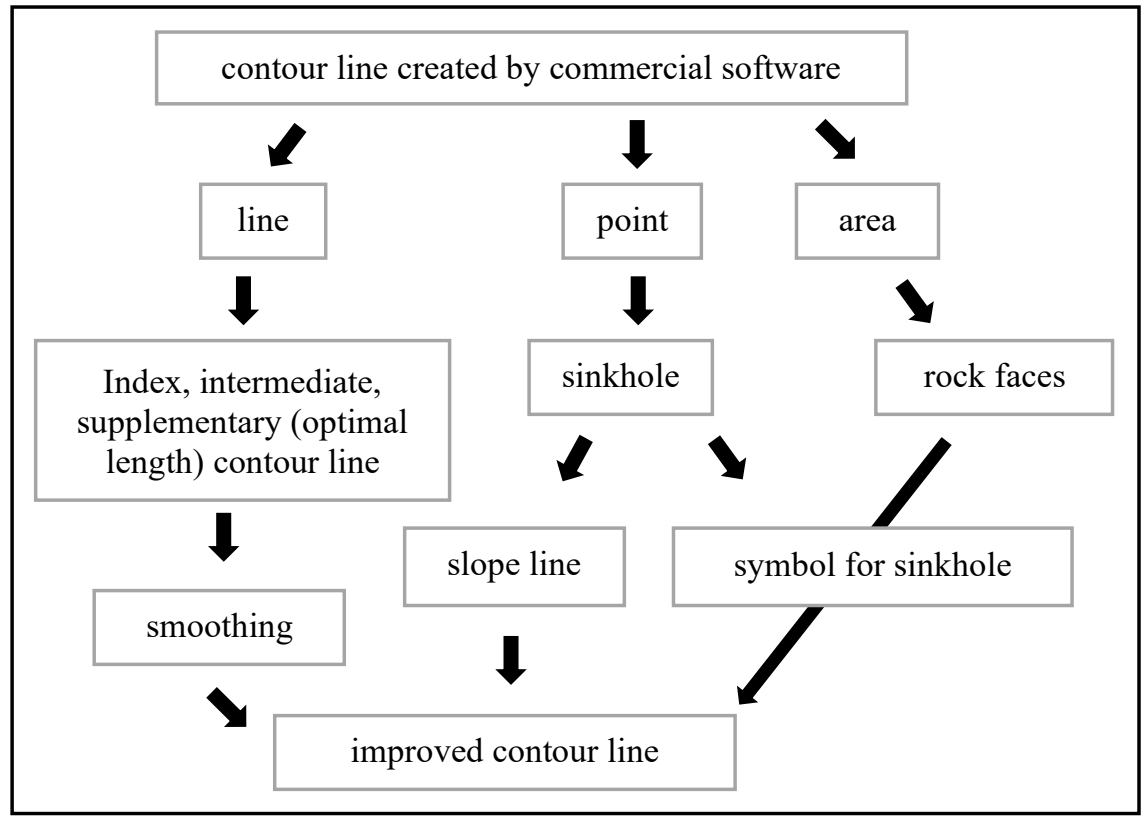

Figure 1. Diagram. 